\title{
Article \\ Effect of Ceramic Capillary Parameters on Bonded Morphology and Strength
}

\author{
Jun Cao ${ }^{1, *(\mathbb{D}}$, Junchao Zhang ${ }^{1}$, Kexing Song ${ }^{2}$, Baoan $\mathrm{Wu}^{3}$, Yong Ding ${ }^{4}$, Dingbiao Chen ${ }^{5}$ and Yutian Ding ${ }^{6}$ \\ 1 School of Mechanical and Power Engineering, Henan Polytechnic University, Jiaozuo 454000, China; \\ zjc_xlyx@sina.com \\ 2 School of Materials Science and Engineering, Henan University of Science and Technology, \\ Luoyang 471000, China; kxsong@haust.edu.cn \\ 3 Chongqing Materials Research Institute Co., Ltd., Chongqing 400700, China; caolinc@163.com \\ 4 Zhejiang Tony Electronic Co., Ltd., Huzhou 313008, China; diego.ding@tony-tech.com \\ 5 Changzhou Hengfeng Special Conductor Co., Ltd., Changzhou 213000, China; pur@czhftc.com \\ 6 School of Materials Science and Engineering, Lanzhou University of Technology, Lanzhou 730050, China; \\ ytding@lut.cn \\ * Correspondence: cavan@hpu.edu.cn
}

Citation: Cao, J.; Zhang, J.; Song, K.; Wu, B.; Ding, Y.; Chen, D.; Ding, Y. Effect of Ceramic Capillary Parameters on Bonded Morphology and Strength. Micromachines 2021, 12, 24. https://doi.org/10.3390/ mi12010024

Received: 11 November 2020 Accepted: 25 December 2020 Published: 29 December 2020

Publisher's Note: MDPI stays neutral with regard to jurisdictional claims in published maps and institutional affiliations.

Copyright: () 2020 by the authors. Licensee MDPI, Basel, Switzerland. This article is an open access article distributed under the terms and conditions of the Creative Commons Attribution (CC BY) license (https: / / creativecommons.org/ licenses/by/4.0/).

\begin{abstract}
The effects of the geometry parameters of a ceramic cleaver on the morphology of ball and second bonded points were studied using an automatic wire bonder, push pull tester, scanning electron microscope, ceramic capillary with different geometric parameters and $\varphi 25.4 \mu \mathrm{mAg}-5 \mathrm{Au}$ bonding alloy wire, etc. The result shows that when the inner hole diameter (IHD) of the ceramic capillary is 1.3 times the diameter of the alloy wire $(33 \mu \mathrm{m})$, the neck morphology of the ball bonded point (first bonded point) meet the requirements. The neck of the ball bonded point appeared to fracture when the IHD is $26 \mu \mathrm{m}$; The neck of the ball bonded point appeared as an irregular shape when the IHD is $41 \mu \mathrm{m}$. When the inner cutting angle diameter (ICAD) is $64 \mu \mathrm{m}$, the size of the mashed ball diameter (MBD) is qualified. When the ICAD is $51 \mu \mathrm{m}$, the MBD is too large and mashed ball overflows the pad. When the ICAD is $76 \mu \mathrm{m}$, the ball bonded point is too high. When the inner cutting bevel angle (ICBA) is $100^{\circ}$, the MBD size meets the requirements of the pad. When the ICBA was reduced to $70^{\circ}$, the ball bonded point is eccentric. When the ICBA was increased to $120^{\circ}$, the MBD is too large and is connected to the adjacent pad contact. The size of the fish tail of the second bonded point (second bonded point) changed in the same direction as the tip diameter (TD) changes. When the TD is $178 \mu \mathrm{m}$, the fish tail shape is regular and symmetrical. When the working face angle (WFA) is $8^{\circ}$ and the outer circular radius (OCR) is equal to the diameter of the alloy wire $(25.4 \mu \mathrm{m})$, the fish tail shape is regular. When the WFA is higher than $11^{\circ}$ or the OCR is higher than $30 \mu \mathrm{m}$, the fish tail will appear as virtual welding, and when the WFA is less than $4^{\circ}$, the fish tail of the second bonded point will break due to thinning. When the OCR is less than $20 \mu \mathrm{m}$, the fish tail of the second bonded point is too long and causes a short circuit.
\end{abstract}

Keywords: ceramic capillary; geometric parameters; bonded point morphology

\section{Introduction}

Bonding is one of the key technologies in microelectronics [1]. As the key tool in wire bonding, the geometric parameters of the ceramic capillary determines the quality and reliability of the chip packaging. Therefore, the choice of ceramic capillary in the field of microelectronics is particularly important for wire bonding [2]. With the booming development of the microelectronics industry, the demand for ceramic capillaries is also increasing [3-5]. At the same time, the application technology of the ceramic capillary in wire bonding needs to be further improved [6-10]. Many scholars have conducted in depth explorations on the composition, structure, motor history [11], vibration characteristics [12] and other aspects of the ceramic capillary, which provide a valuable reference for the 
parameter design of the ceramic capillary, and promote the more efficient application of the ceramic capillary in the field of microelectronics. For example, Yao Li et al. [13] found that if the outer circular radius (OCR) is too large, the length of the bonded point will be too small, hence the bonded points will be weak. On the contrary, if the OCR is too small, the length of the bonded points will be too large, resulting in the interconnection of adjacent bonded points and the package failure. Goh K S et al. [14] found that the cone core angle, the inner cutting bevel angle (ICBA) and the inner cutting angle diameter (ICAD) have a significant effect on the formation of deformed golden balls. A ceramic capillary with a small cone core angle and large ICBA can reduce the diameter of the gold ball by $12 \%$. Kim I J et al. [15] studied the effect of modified doping on the ceramic capillary. The experimental results show that the change of micro grain size improves the strength, hardness, Young's modulus, toughness and surface strength of ceramic capillary. Cao Jun et al. [16] studied the influence of bonding parameters on the bonding performance of copper wires, concluded that excessive ultrasonic power and bonding pressure caused cracks in the bonded points, and insufficient ultrasonic power would result in false welding. Qin Wen et al. [17] and Xue Rui et al. [18] studied the effect of bonding process parameters on the bonding quality of gold wire by using the finite element method and experimental method respectively, and improved the production process. The above-mentioned research mostly focused on the composition, structure, bonding parameters and other aspects of the capillary, while the influence of geometric parameters of the ceramic capillary on the bonded point morphology and bonding quality is rarely discussed. In this paper, by contrasting and researching the different geometric parameters of the ceramic capillary, the bonding experiment is carried out with $\varphi 25.4 \mu \mathrm{m} \mathrm{Ag}-5 \mathrm{Au}$ bonding alloy wire, and the influence of the geometric parameters of the ceramic capillary on the morphology of the alloy wire ball bonded point and second bonded point is analyzed. Additionally, we provide a theoretical basis for the optimization of the geometric parameters of the ceramic capillary.

\section{Materials and Methods}

\subsection{Test Materials}

The bonding wire material is $\varphi 25.4 \mu \mathrm{m} \mathrm{Ag-5Au}$ bonding alloy wire, and the composition and mechanical properties of alloy wire are shown in Table 1. The different geometric parameters of the ceramic capillary are shown in Table 2.

Table 1. Alloy wire element content and mechanical properties table.

\begin{tabular}{ccccc}
\hline & Ag Content (\%) & Au Content (\%) & Strength (N) & Elongation (\%) \\
\hline Ag-5Au & 95 & 5 & 0.095 & 14.1 \\
\hline
\end{tabular}

Table 2. Ceramic capillary geometric parameter table.

\begin{tabular}{ccccccc}
\hline Items & IHD $(\mu \mathrm{m})$ & ICAD $(\mu \mathrm{m})$ & ICBA $\left(^{\circ}\right)$ & TD $(\mu \mathrm{m})$ & WFA $\left(^{\circ}\right)$ & OCR $(\mu \mathrm{m})$ \\
\hline 1 & 33 & 64 & 100 & 178 & 8 & 25.4 \\
2 & 26 & 64 & 100 & 178 & 8 & 25.4 \\
3 & 41 & 64 & 100 & 178 & 8 & 25.4 \\
4 & 33 & 51 & 100 & 178 & 8 & 25.4 \\
5 & 33 & 76 & 100 & 178 & 8 & 25.4 \\
6 & 33 & 64 & 70 & 178 & 8 & 25.4 \\
7 & 33 & 64 & 120 & 178 & 8 & 25.4 \\
8 & 33 & 64 & 100 & 127 & 8 & 25.4 \\
9 & 33 & 64 & 100 & 241 & 8 & 25.4 \\
10 & 33 & 64 & 100 & 178 & 4 & 25.4 \\
11 & 33 & 64 & 100 & 178 & 11 & 25.4 \\
12 & 33 & 64 & 100 & 178 & 8 & 20.0 \\
13 & 33 & 64 & 100 & 178 & 8 & 30.0 \\
\hline
\end{tabular}


The structure of ceramic capillary is very precise and complex $[19,20]$, as shown in Figure 1.

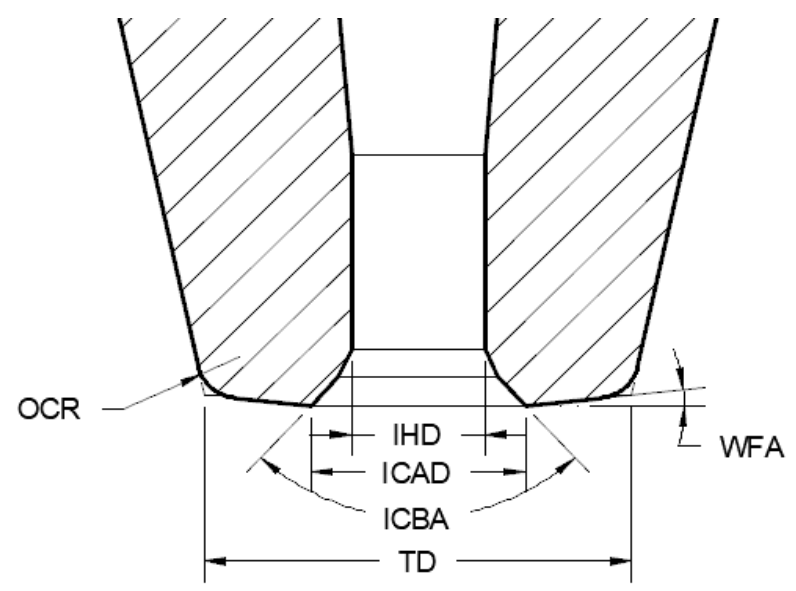

Figure 1. The main parameters of the ceramic capillary: IHD; ICAD; ICBA; TD; WFA; OCR [21].

\subsection{Test Method}

The bonding test was performed on the KAIJO FB-988 automatic bonding machine using $\varphi 25.4 \mu \mathrm{m}$ Ag-5Au bonding alloy wire, $\mathrm{N}_{2}$ gas protection is used in the bonding process, and the gas flow rate is $0.6 \mathrm{~L} / \mathrm{min}$ [22]. Wire bonding can be divided into ball bonding and second bonding according to the bonded point shape [23-27]. The bonding parameters of the ball bonded point are ultrasonic power $60 \mathrm{~mW}$, bonding pressure $45 \mathrm{~g}$; The bonding parameters of the second bonded point are ultrasonic power $95 \mathrm{~mW}$, bonding pressure $75 \mathrm{~g}$. Using the method of controlling variables, under the condition of the ultrasonic power, bonding pressure and other process parameters remain unchanged, we changed the IHD, ICAD, ICBA, tip diameter (TD), working face angle (WFA), outer circular radius (OCR) of the ceramic capillary, and then conducted a grouping test. A JEOL JSM-6700F scanning electron microscope was used to research and analyze the morphology of the ball bonded points and second bonded points. A Dage Series 4000, BS250 tester was used to test the ball shear strength and pull strength of the ball bonded points, and to analyze the influence of different geometric parameters of the capillary on the ball shear strength and pull strength. The ball shear strength test is shown in Figure 2, and the tensile test is shown in Figure 3. The tensile test fracture positions are A, B, C, D, where the break at point $A$ is the ball detachment, the point $B$ is the broken neck, the point $C$ is the broken middle, and the point $\mathrm{D}$ is the neck fracture of the second bonded point. Breakpoints at point $\mathrm{A}, \mathrm{B}$, and $\mathrm{D}$ are all abnormal breaks, and breakpoints at the middle point of $\mathrm{C}$ and $\mathrm{D}$ are normal breaks.

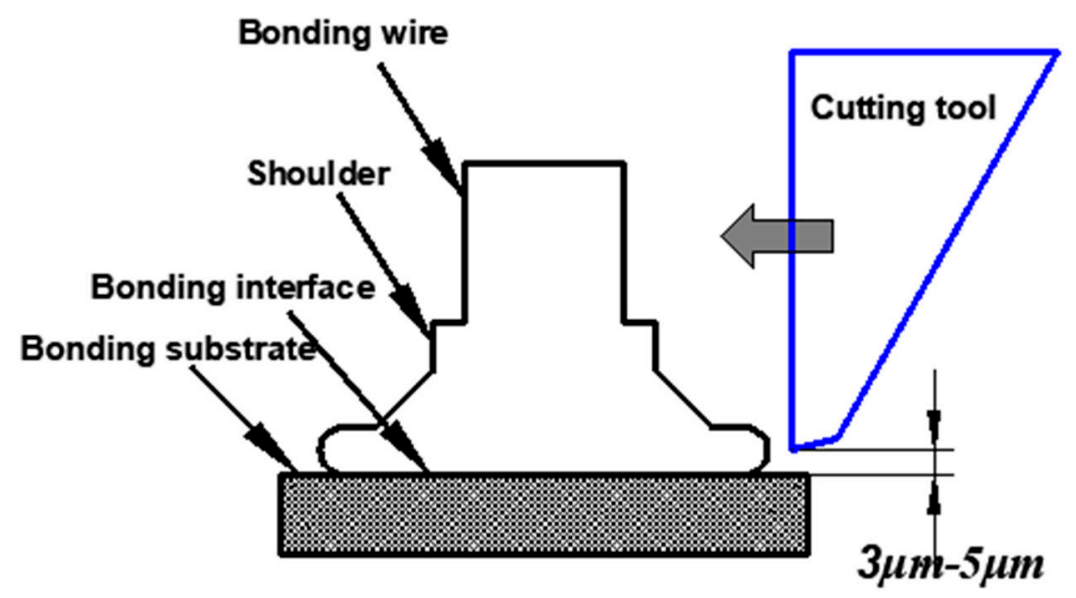

Figure 2. Schematic diagram of the ball bonded point shear test. 




Figure 3. Schematic diagram of tensile test and breaking position.

\section{Results}

\subsection{The Research on the Influence of IHD on the Morphology of Bonded Point}

A free air ball (FAB) is formed by bonding alloy wire under the action of ball burning current [28], and the diameter of the FAB is generally 2-3 times of wire diameter [29-33]. The diameter of the FAB is $66.76 \mu \mathrm{m}$ (2.63 times the diameter of alloy wire) in the test, which meets the test requirements. As shown in Figure 4, the FAB changes into the shape of the ball bonded point formed under the action of bonding power, pressure and temperature by force of a ceramic capillary. Figure 5 shows the morphology of the ball bonded points with the different IHD. When the IHD is $33 \mu \mathrm{m}$, the shape of the neck of the ball bonded point is regular and symmetrical, and the perpendicularity with the bonded point is better; the ball bonded point has a thin neck and irregular shape when the IHD is $26 \mu \mathrm{m}$. The neck of the ball bonded point deviates greatly from the center when the IHD is $41 \mu \mathrm{m}$.

The IHD of the ceramic capillary is a key parameter for the formation of the neck of the ball bonded point, which determines the morphological characteristics and strength of the neck of the ball bonded point. During the bonding process, the bonding alloy wire forms a neck feature perpendicular to the ball joint under the action of the capillary. The neck with high perpendicularity has less internal stress, the neck strength of the ball joint is high, hence the probability of neck breakage after bonding is low.

Figure 6 shows the distribution of the pull strength of the ball bonded points when the IHD of ceramic capillary is 26,33 and $41 \mu \mathrm{m}$, respectively. The minimum values are $2.68,11.26$ and $8.11 \mathrm{~g}$, respectively. Only when the IHD is $33 \mu \mathrm{m}$ the ball bonded point tension has the largest average value- $11.26 \mathrm{~g}$, and the fluctuation range of the tension value is smallest. In the other two cases, the average value of pull strength is small and the distribution range is large, so the bonding strength is not good enough.

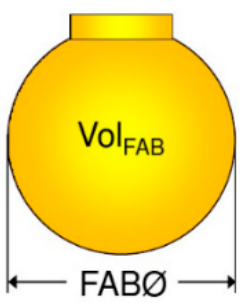

Free Air Ball

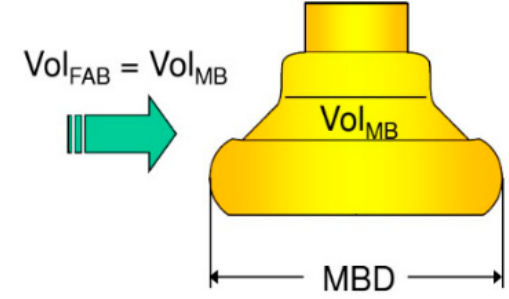

Mashed Ball Diameter

Figure 4. Comparison of the morphology of the ball bonded point before and after bonding. 

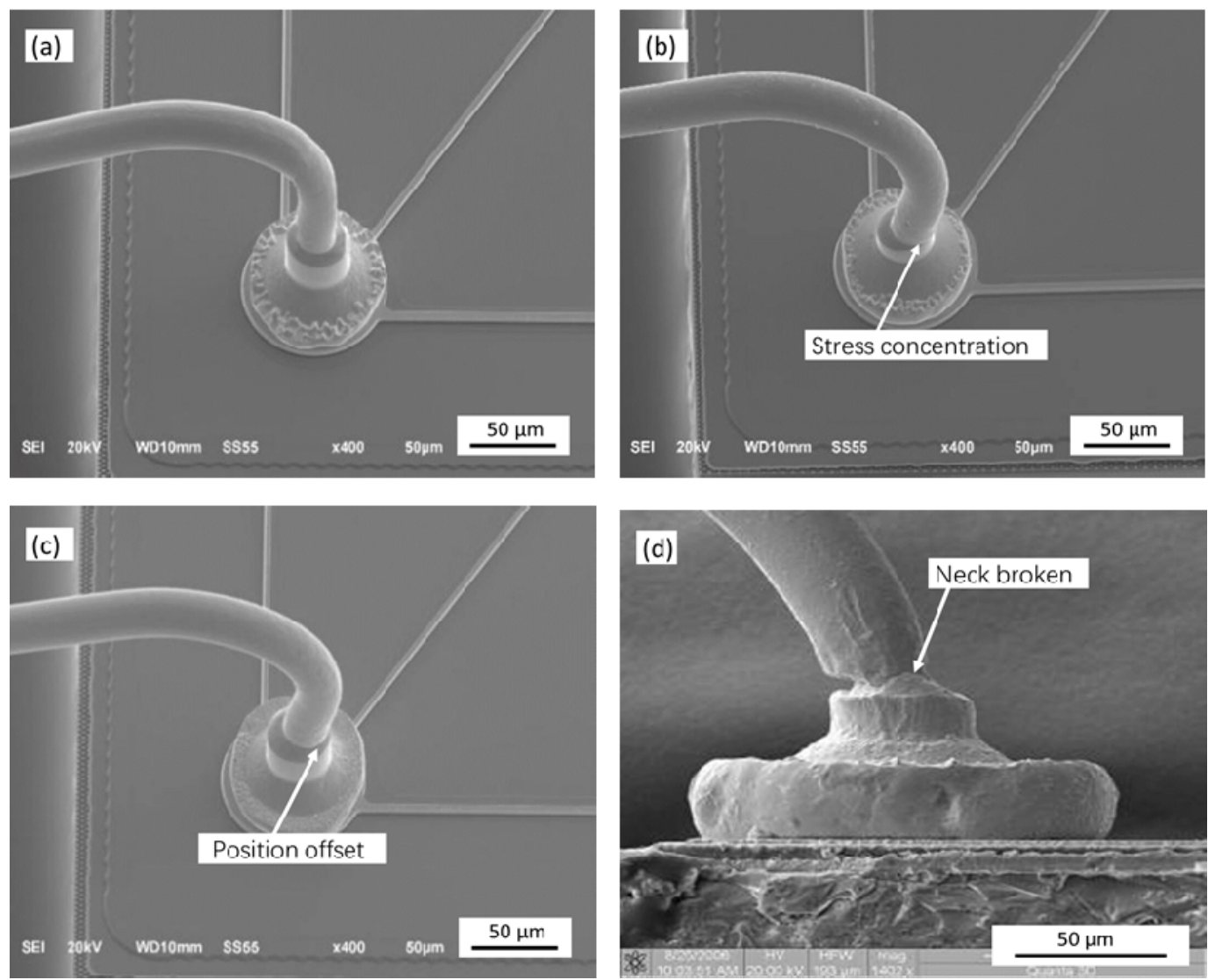

Figure 5. The morphology of the ball bonded points with the IHDs of: (a) $33 \mu \mathrm{m}$; (b) $26 \mu \mathrm{m}$; (c) $41 \mu \mathrm{m}$; (d) the neck fracture of the ball bonded point caused by the small IHD of the capillary.

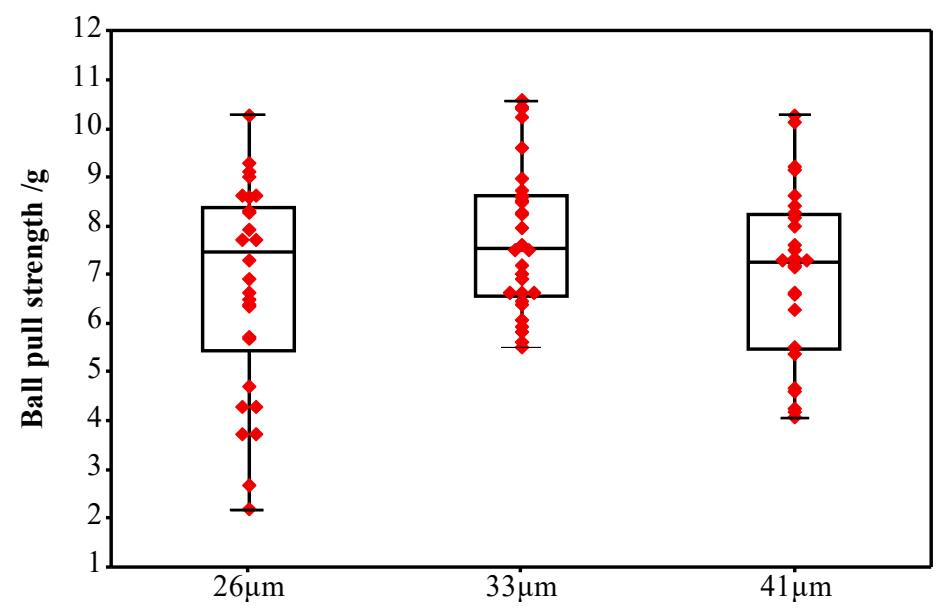

Figure 6. The pull strength of the ball bonded points with IHDs of 26,33 and $41 \mu \mathrm{m}$ respectively.

When the IHD of the capillary is $26 \mu \mathrm{m}$, the gap between the inner hole wall of the capillary and the alloy wire is $0.5 \mu \mathrm{m}$. The friction force increases between alloy wire and inner hole wall during the bonding process, which causes the ball bonding neck to shift, and the deformation rate increases, and then the pull strength value of the ball bonded point decreases. The neck of the ball bonded point is fractured due to the large deformation rate when the friction force is further increased, as shown in Figure $5 d$, even the partial tension value is heavily reduced, as shown in Figure 6. When the IHD of the ceramic capillary is $41 \mu \mathrm{m}$, the gap between the inner hole wall of the ceramic capillary and the alloy wire increases due to the large IHD, resulting in a low coaxiality between the alloy wire and the inner hole of the ceramic capillary and the neck of the ball bonded point is 
not symmetrical due to the alloy wire is not fixed enough during bonding. Finally, it leads to a decrease in the strength of the neck of the ball bonded point during service. When the IHD of the ceramic capillary is 1.3 times $(33 \mu \mathrm{m})$ of the wire diameter, the neck shape of the bonding ball bond is regular and the symmetry is good, which meets the requirements of ball bonding characteristics.

Figure 7 is a statistical diagram of the position of the bonded point breakpoints after the bonding test of the ceramic capillary with different IHDs. It shows that only when the IHD is $33 \mu \mathrm{m}$ the bonding strength is highest and almost all breakpoints (99\%) are in the middle of the bonding wire. The breakpoints at point $B$ indicates that the bonding strength between the ball bonded point and the substrate is lower than that of the bonding wire itself. The above data verify the conclusion that the bonding strength of the ball bonded point will decrease-whether the IHD of the ceramic capillary is too large or too small.

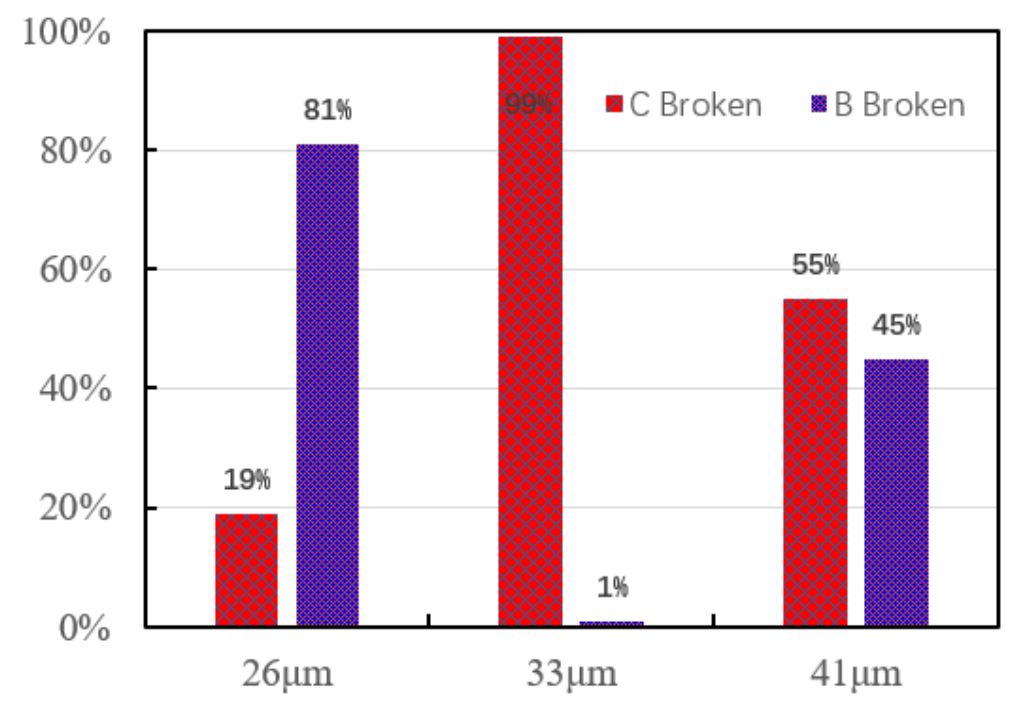

Figure 7. Statistical diagram of the breakpoint position of the ball bonded point with IHDs of 26,33 and $41 \mu \mathrm{m}$ respectively.

\subsection{The Research on the Influence of the ICAD on the Morphology of the Bonded Point}

Figure 8 is the morphology of the ball bonded points with. When the ICAD is $64 \mu \mathrm{m}$, the MBD size is distributed inside the pad thus meet the bonding requirements; when the ICAD is $51 \mu \mathrm{m}$, the MBD size is too large and overflows the pad, causing a short circuit and device failure; When the ICAD is $76 \mu \mathrm{m}$. the MBD bottom of the bonded point is too high, which reduces the radial size of the MBD and the bonding area between the bottom of the bonded point and the pad. The shearing force and reliability of the bonded point are reduced.

The bonding strength between the bonding wire and the pad is determined by the contact surface between the bonded point and the pad. Increasing the contact area between the bonded point and the pad is beneficial to improve the bonding strength of the bonding interface. The ICAD of the capillary determines the morphology of the ball bonded point. Within the size of the pad, the MBD of the ball bonded point, the contact area between the bonded point and the pad, and the shear strength of the bonding ball all increase with the decrease of the ICAD. As shown in Figure 9, when the ICAD is 51, 64 and $76 \mu \mathrm{m}$, the average shear strength is $49.67,62.71$ and $63.20 \mathrm{~g}$, respectively. Figure $8 \mathrm{~d}$ shows that the ball bonded point will be heavily deformed due to the too small ICAD $(51 \mu \mathrm{m})$, and even overflow the pad to cause a short circuit and device failure. When the ICAD is larger than $76 \mu \mathrm{m}$, the height of the ball bonded point will increase more, and due to the volume of the ball bonded point remains unchanged, so the MBD of the ball bonded point decreases and the bonding strength decreases. In addition, the high MBD is easy to cause neck fracture 
and lead to bonding failure in the process of high density packaging. Only when the ICAD is $76 \mu \mathrm{m}$, the morphology and strength uniformity of the ball bonded point are the best.
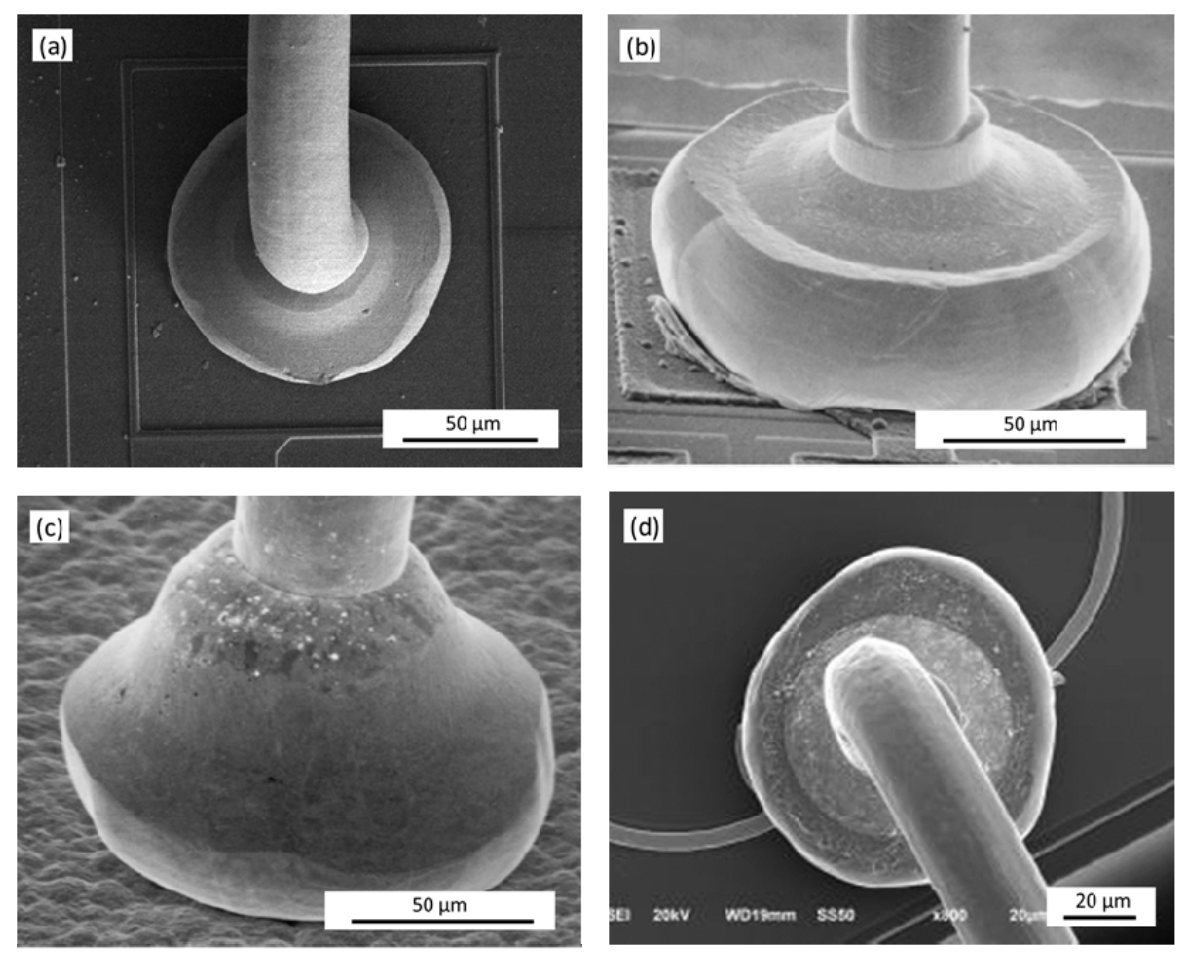

Figure 8. The shape of the ball bonded point with ICADs of: (a) $64 \mu \mathrm{m}$; (b) $51 \mu \mathrm{m}$; (c) $76 \mu \mathrm{m}$; (d) the MBD is too large and overflows the pad due to the small ICAD.

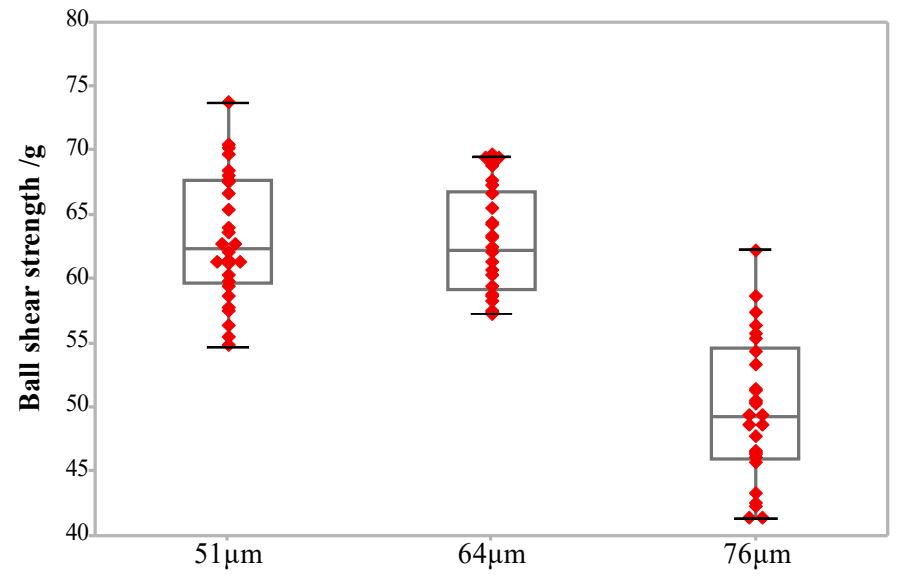

Figure 9. The shear strength of the ball bonded points when the ICAD is 51, 64 and $76 \mu \mathrm{m}$.

\subsection{Research on the Influence of ICBA on Bonded Point Morphology}

The Figure 10 shows the morphology of the ball bonded points with the different ICBA. It can be seen from the Figure 10a that the MBD is distributed within the size of the pad and the bonded point morphology is good when the ICBA is $100^{\circ}$. When the ICBA is $70^{\circ}$, the MBD is within the size of the pad, but the contact area with the pad is small and the shear strength and the bonding strength is low. When the ICBA is $120^{\circ}$, the MBD size obviously exceeds the pad specification, causing the adjacent ball bonded points to contact, the bonded point to short circuit and the device invalidate. 

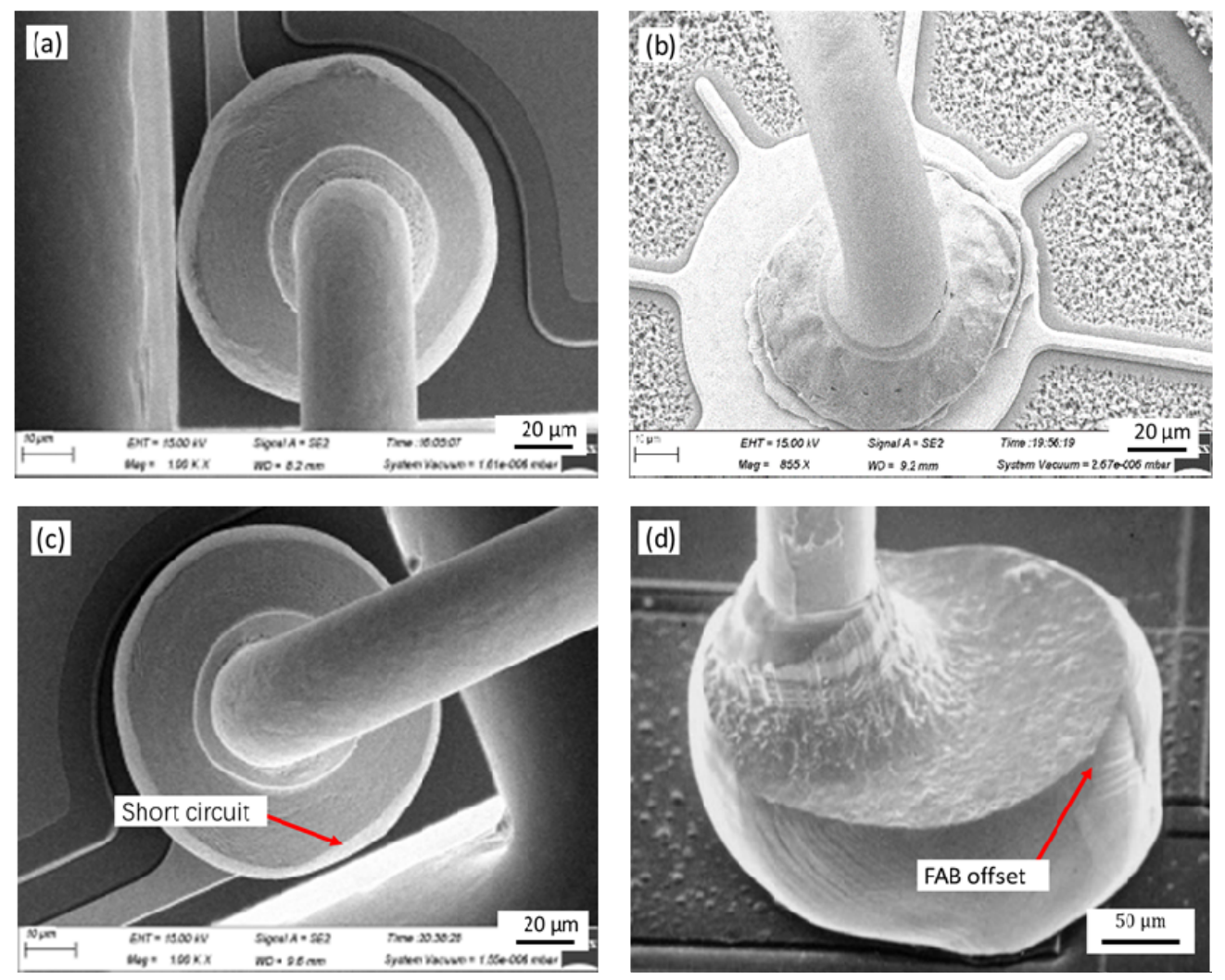

Figure 10. The morphology of the ball bonded points ICBAs of: (a) $100^{\circ}$; (b) $70^{\circ}$; (c) $120^{\circ}$; (d) the ICBA is so small that it forms an eccentric ball.

Figure 11 shows the ball shear strength and pull strength of the ball bonded point when the ICBA of the ceramic capillary is $70^{\circ}, 100^{\circ}$ and $120^{\circ}$, respectively (all breakpoints are between Figure 10C,D in this test). It can be seen from Figure 11 that the average shear strength is $51.99,63.50$ and $70.56 \mathrm{~g}$ respectively, and the average pull strength is $6.87,7.48$ and $7.29 \mathrm{~g}$, respectively. It can be seen that, with the increase of ICBA, the contact area between the ball bonded point and the pad increases, so the shear strength of the ball bonded point increases. However, the neck of the ball bonded point is not affected by ICBA. Therefore, the pull strength of the ball bonded point remains basically unchanged.
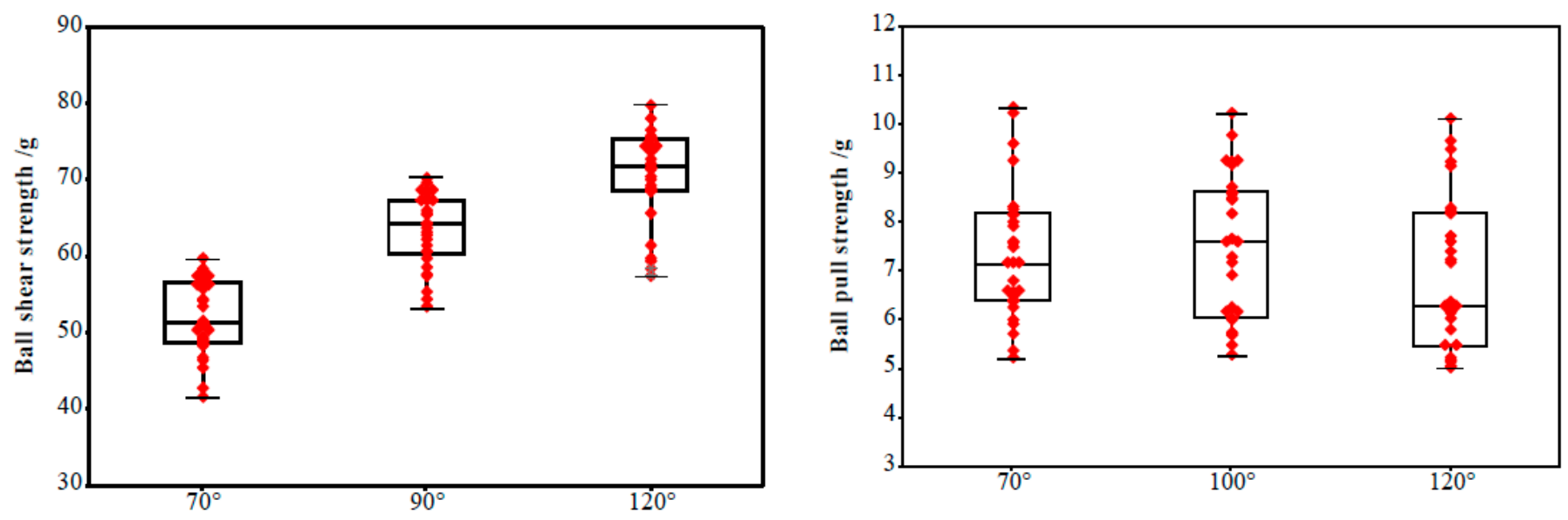

Figure 11. The shear strength and pull strength statistics of the ball bonded points with the different ICBA.

With the increase of the ICBA of the capillary, the MBD size, the contact area between the ball bonded point and the pad, the shear strength of the ball bonded point all increase, 
and the ball bonded point has good reliability. However, in the case of the ICBA being greater than $120^{\circ}$, the MBD of the ball bonded point will be too close to the adjacent ball bonded points, which results in a short circuit of the bonded point, as shown in Figure 10c. When the ICBA decreases, the height of the ball bonded point increases and the probability of false welding increases because the FAB volume remains unchanged and the MBD of the ball bonded point decreases. In addition, the height of the ball bonded point increases, the neck deformation rate of the ball joint becomes larger, and the stress concentration is more obvious, which reduces the reliability of the ball bonded point; When the ICBA is less than $70^{\circ}$, the control degree of the tip of the capillary on the FAB position is reduced, and the eccentric ball is easy to form in the bonding process, the bonding strength is reduced, and the short circuit probability of the ball bonded point is increased, as shown in Figure 10d.

\subsection{Research on the Influence of TD on Bonded Point Morphology}

Figure 12 shows the morphology of the second bonded points with the different TD. When the TD is $178 \mu \mathrm{m}$, the second bonded point is in the shape of a symmetrical fish tail and distributed with a small power ring mark; when the TD is $127 \mu \mathrm{m}$, the second bonded point is similar to a fish tail shape, but has less extension on both sides and no power ring mark; when the TD is $241 \mu \mathrm{m}$, the second bonded points are regular, the fish tail shape is symmetrically distributed, and the power ring mark is complete.
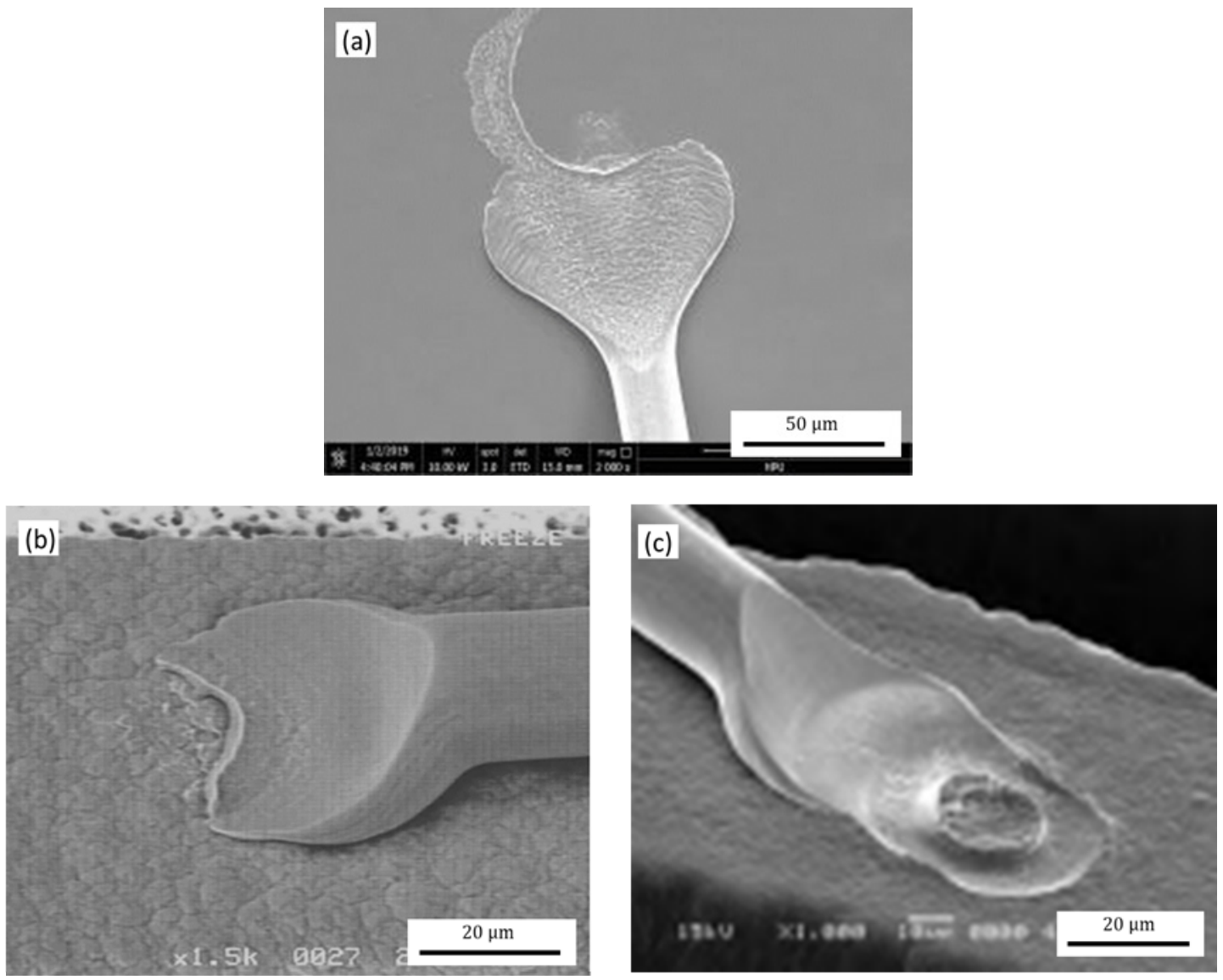

Figure 12. The morphology of the second bonded points with tip diameters (TDs) of: (a) $178 \mu \mathrm{m}$; (b) $127 \mu \mathrm{m}$; (c) $241 \mu \mathrm{m}$.

The tip of the capillary is the main stress surface that forms the second bonded point, and the TD of the capillary is one of the main factors that form the morphology and bond strength of the second bonded point [34]. In Figure 13, as the TD increases, the fish tail shape after bonding is larger, the contact area between the second bonded point and the pad is increased, and the bonding strength and reliability of the bonded point are improved. However, due to the limited distance between the pads, the TD is too large to easily contact 
the adjacent bonding alloy wires during the bonding process, causing mutual interference in the bonding process, reducing the bonding efficiency and bonding accuracy. Reducing the TD of the ceramic capillary is beneficial to the bonding of fine pitch pads, but when less than $127 \mu \mathrm{m}$, it will cause the second bonded point to be too small, and the contact area between the second bonded point and the pad will decrease, which easily causes bonded points to fall off and the bonded point to fail. Therefore, in the bonding process, within the allowable range of the pad size, a ceramic capillary with a larger TD should be selected as much as possible. For the $\varphi 25.4 \mu \mathrm{m} \mathrm{Ag}-5 \mathrm{Au}$ bonding alloy wire, when the TD is $241 \mu \mathrm{m}$, it has a good bonded point morphology: symmetrically distributed fish tail shape, completed power ring mark and better bonding strength.

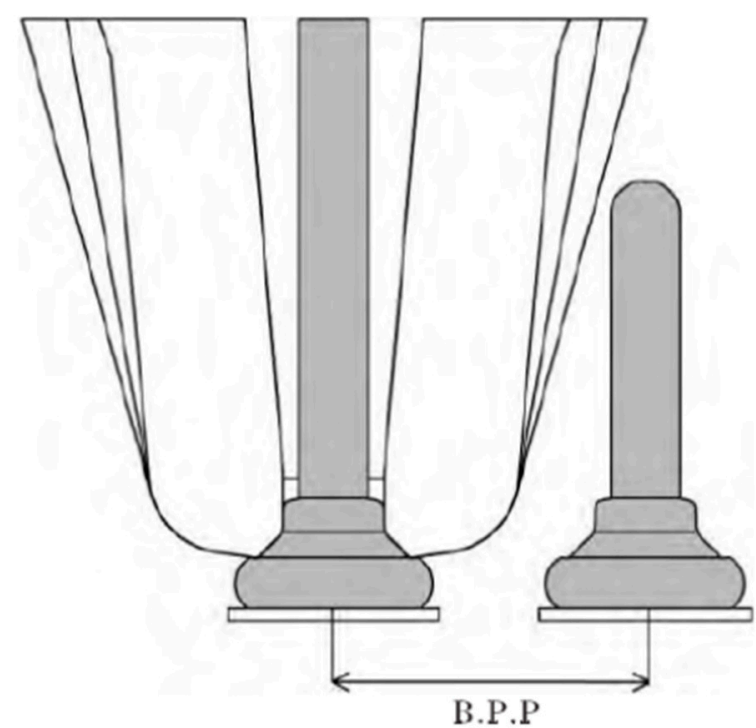

Figure 13. Schematic diagram of wire bonding pitch space of bonding pad.

\subsection{Research on the Influence of WFA on Bonded Point Morphology}

Figure 14 shows the second bonded points morphology with the different WFA of the ceramic capillary. The second bonded points are fish-tailed and symmetrically distributed, and produce semicircular power ring mark when WFA is $8^{\circ}$; when the WFA is $4^{\circ}$, the second bonded point is in the shape of an asymmetric fishtail, but its power ring mark is circular; when WFA is $11^{\circ}$, which the second bonded point has an asymmetric fishtail shape and there is no power ring mark.

The smaller the WFA of the ceramic capillary is, the greater the vertical bonding force pressure applied to the second bonded point on the working face, and the ultrasonic energy transmission also increases. The combined effect of the bonding alloy wire at high temperature, bonding pressure and ultrasonic energy mechanical coupling occurs between the bottom and the substrate metal, the length of the power loop increases [35], and the bonding strength of the second bonded point is improved. Figure 15 shows the pulling force value of the second bonded point of the bonding alloy wire with different WFAs, when the capillary WFA is $8^{\circ}$, the bond alloy wire second bonded point tensile value is the largest, with an average value of $6.82 \mathrm{~g}$. When the capillary WFA is $4^{\circ}$ and $11^{\circ}$, the average bonding alloy wire second bonded point pull strength is 4.88 and $4.71 \mathrm{~g}$ respectively. 

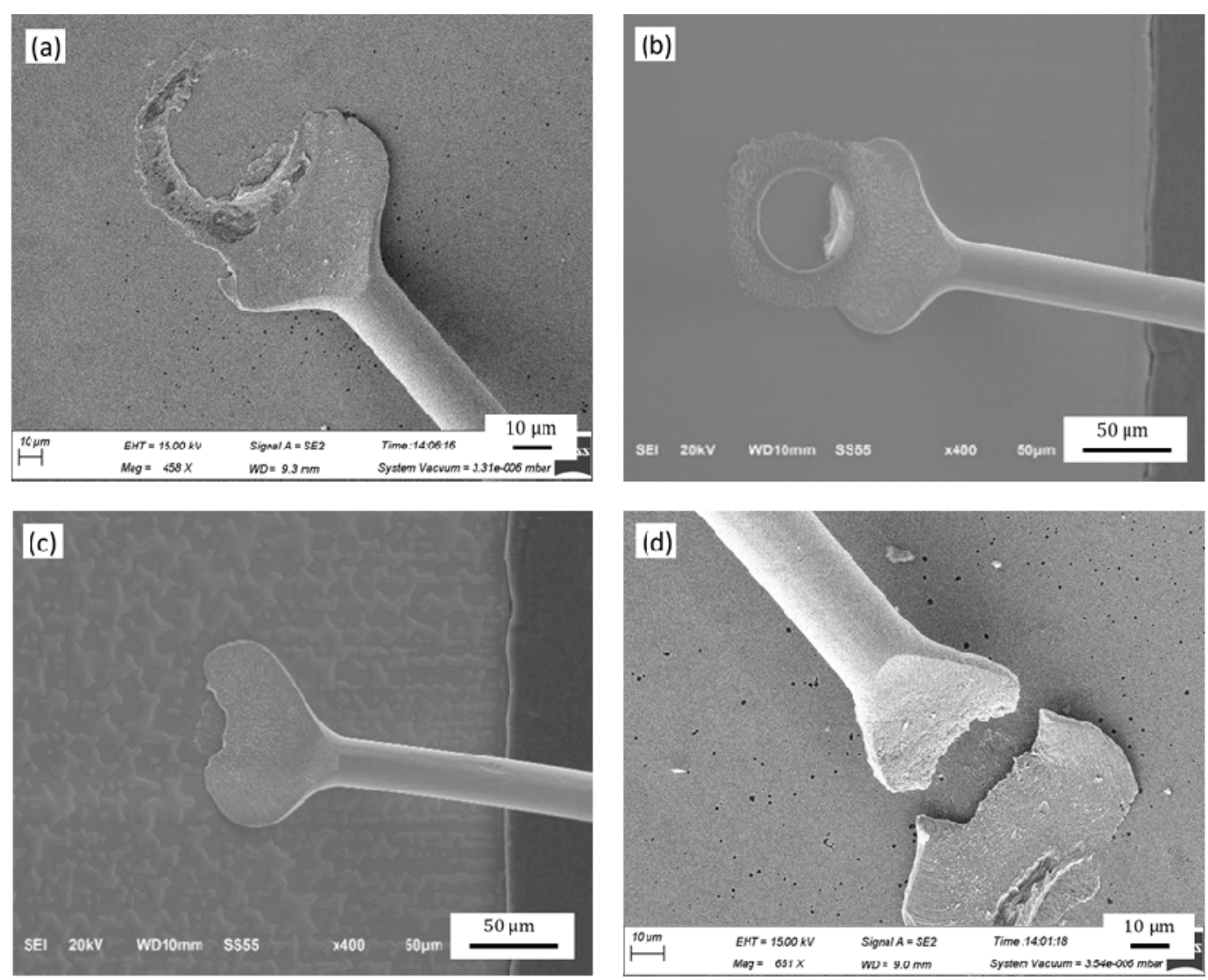

Figure 14. The topography of the second bonded points with WFAs of: (a) $8^{\circ}$; (b) $4^{\circ}$; (c) $11^{\circ}$; (d) second bonded point fracture due to the small WFA.

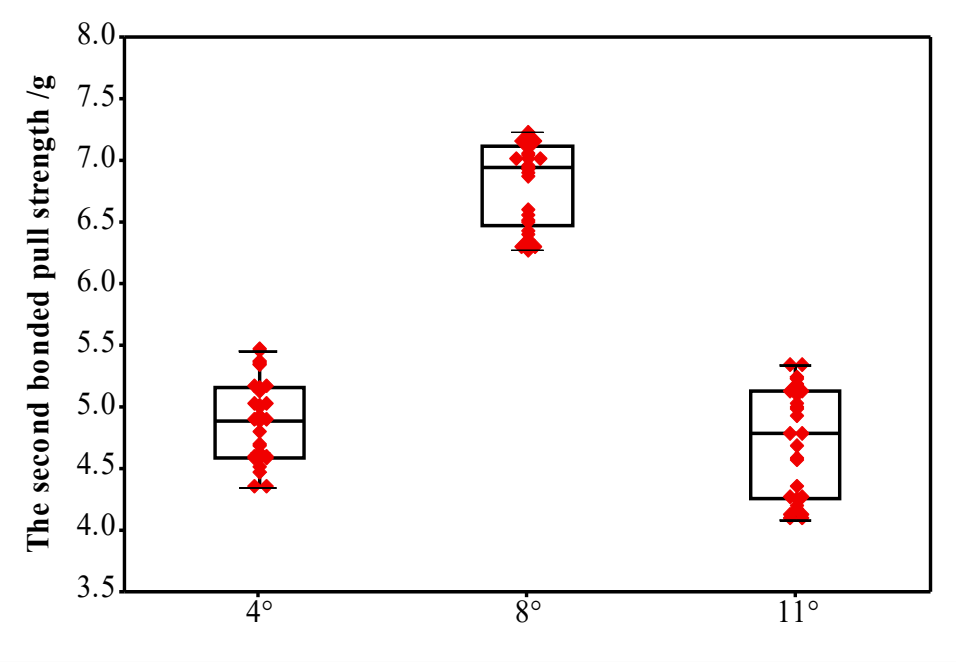

Figure 15. The pull strength of the second bonded point alloy wire when the WFA is $4^{\circ}, 8^{\circ}$ and $11^{\circ}$.

When the WFA is less than $4^{\circ}$, it will reduce the force area of the fish tail of the second bonded point, resulting in greater force on the fish tail, making the fish tail too thin, that reduces the bonding strength and even breaks at the tip edge of the second bonded point failure, as shown in Figure 14d. Increasing the WFA, the fishtail thickness of the second bonded point and the bonding area will also increase, thereby improving the strength of the second bonded point and the reliability. However, when the WFA is greater than $11^{\circ}$, the vertical downward bonding area of the ceramic capillary to the second bonded point will increase more, while the pressure at the fish tail, the deformation rate and the bonding 
strength will decrease, causing virtual welding and even resulting in the bonding being invalidated.

\subsection{Research on the Influence of OCR on Bonded Point Morphology}

Figure 16 shows the morphology of the second bonded point with the different OCR of the capillary. When the OCR is $25.4 \mu \mathrm{m}$, in which the second bonded point has a fish-tail shape, the thickness gradually increases from the ceramic capillary working surface to the tip edge. When the OCR is $20 \mu \mathrm{m}$, the second bonded point is in the shape of a fish tail, but the shape variable is larger. When the OCR is $30 \mu \mathrm{m}$, the second bonded point has a fish-tail morphology, but the effective bond length between the fish tail and the pad is relatively short, so the bonding strength is low.
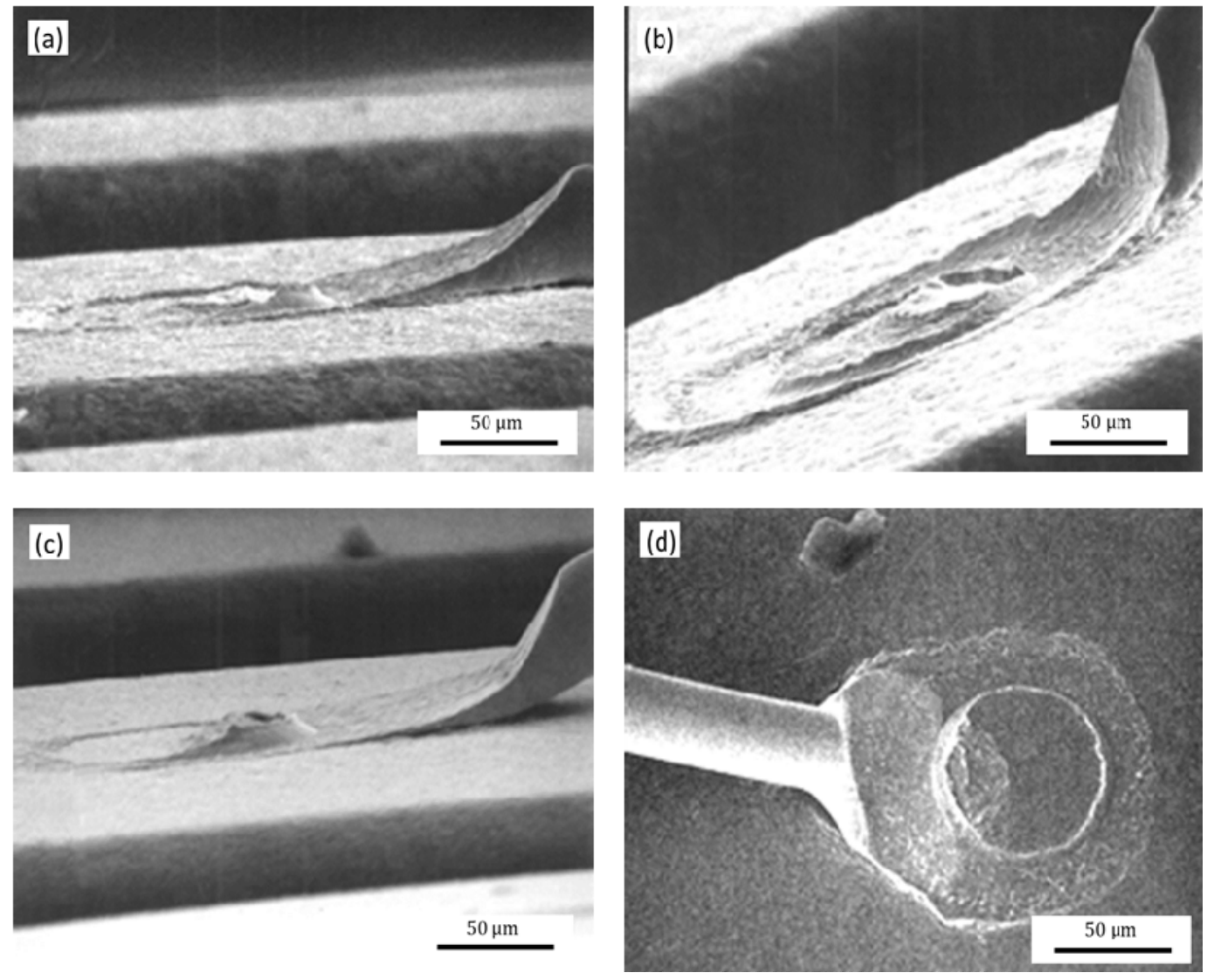

Figure 16. The morphology of the second bonded point when the OCR is: (a) $25.4 \mu \mathrm{m}$; (b) $20 \mu \mathrm{m}$; (c) $30 \mu \mathrm{m}$; (d) the second bonded point with small OCR.

The OCR of the ceramic capillary determines the transition characteristics from the working face of the ceramic capillary to the tip edge. During the bonding process, the bonding alloy wire is deformed under the action of the outer circular, and gradually transitions from flattening and bonding to a complete bonding alloy wire [36]. The tension values of the second bonded points of the capillary when the OCR is 20, 25.4 and $30 \mu \mathrm{m}$, respectively, are shown in Figure 17. The average values of pull strength are 4.89, 6.56 and $5.59 \mathrm{~g}$, respectively. The larger the OCR of the capillary, the smaller the area of the bonding alloy wire affected by the top of the capillary during the bonding process, the shorter the length of the second bonded point formed, and the longer the second bonded point length. When the OCR is $30 \mu \mathrm{m}$, the deformation area of the second bonded point will be larger, the effective contact area between the bonded point and the pad and the bonding strength will be smaller; When the OCR is $20 \mu \mathrm{m}$, the force area of alloy wire second welding point decreases. The fish tail area and shape variable of second welding point increases, but its 
effective bonding area with the substrate decreases, resulting in the reduction of bonding tensile value. Furthermore, it is easy to contact with adjacent bonded points, even causing short circuits and package failure due to the increase in fishtail shape and area, as shown in Figure 16d. When the OCR is $25.4 \mu \mathrm{m}$, that is, when the OCR is equal to the diameter of the bonding alloy wire, the bonding morphology is more regular and the bonding strength is higher.

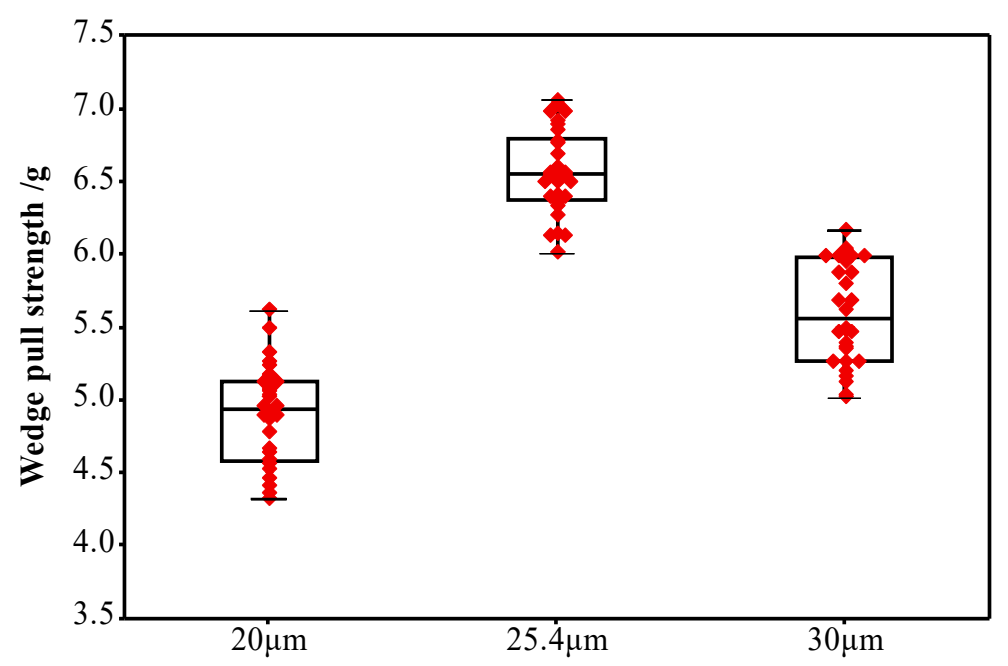

Figure 17. The tensile value of the second bonded points of alloy wires with OCRs of 20, 25.4 and $30 \mu \mathrm{m}$.

\section{Conclusions}

In this paper, by studying the influence of the geometric parameters of the ceramic capillary on the morphology and strength of the $25.4 \mu \mathrm{m} \mathrm{Ag-5Au}$ bonding alloy wire ball bonded point and second bonded point, the following conclusions are drawn.

(1) When the diameter of the inner hole of the ceramic capillary is 1.3 times $(33 \mu \mathrm{m})$ of the diameter of the bonding alloy wire, the morphology of the MBD neck of the ball bonded point meets the requirements, and the increase or decrease of the IHD will cause the MBD neck of the ball bonded point irregular and reduced tensile strength.

(2) When one of the ICAD or the ICBA of the ceramic capillary remains unchanged, the MBD size of the ball bonded point increases with the decrease of the ICAD or the increase of the ICBA. When the ICAD and ICBA is $64 \mu \mathrm{m}$ and $100^{\circ}$, respectively. The size of the ball joint MBD meets the specifications.

(3) The bonding strength and the contact area between the second bonded point and the pad increase with the increase of the TD of the capillary. However, the TD is too large to make the capillary contact the adjacent bonding wire, reducing the bonding accuracy. When the TD is $241 \mu \mathrm{m}$, the second bonded point has a good shape.

(4) When one of the WFA and the OCR of the ceramic capillary remains unchanged, the fishtail shape of the second bonded point decreases with the increase of the WFA or the OCR. When the WFA and the OCR are respectively at $8^{\circ}$ and $25.4 \mu \mathrm{m}$, the second bonded points are in a regular and symmetrical fishtail shape, and the power ring imprinting is complete.

Author Contributions: Conceptualization, J.C.; methodology, J.C.; software, D.C., J.Z.; validation, J.C., J.Z.; formal analysis, K.S.; investigation, B.W.; resources, B.W.; data curation, J.C.; writingoriginal draft preparation, J.Z.; writing — review and editing, J.C.; visualization, Y.D. (Yong Ding); supervision, Y.D. (Yutian Ding); project administration, J.C.; funding acquisition, J.C. All authors have read and agreed to the published version of the manuscript.

Funding: This research was funded by key scientific and technological projects in Henan Province China, grant number 193102210007. 
Data Availability Statement: The data presented in this study are available in article.

Conflicts of Interest: The authors declare no conflict of interest.

\section{References}

1. Ly, N.; Xu, D.E.; Song, W.H.; Mayer, M. More uniform Pd distribution in free air balls of Pd-coated Cu bonding wire using movable flame off electrode. Microelectron. Reliab. 2015, 55, 201. [CrossRef]

2. Liu, P.S.; Tong, L.Y.; Wang, J.; Shi, L.; Tang, H. Challenges and developments of copper wire bonding technology. Microelectron. Reliab. 2012, 52, 1092. [CrossRef]

3. Yu, X. China's sealing and testing industry is rising. China's Strateg. Emerg. Ind. 2017, 33, 56-57.

4. Zhang, M. Overview of modern power electronics integration technology. High Power Convert. Technol. $2016,1,1-7$.

5. Wang, J. Development of electronic packaging and micro assembly sealing technology. Electron. Technol. 2011, 32, 197-201.

6. Murali, S.; Srikanth, N.; Vath Charles, J. An Analysis of Intermetallics Formation of Gold and Copper Ball Bonding on the rmalAging. Mater. Res. Bull. 2003, 38, 637-646. [CrossRef]

7. Hang, C.J.; Tian, Y.H.; Pelzer, R.; Zink, R.; Wöhlert, S.; Nelhiebel, M. High temperature storage reliability of Cu bonds by ultrasonicbonding with fine copper wire. Trans. China Weld. Inst. 2013, 34, 13-16.

8. Tseng, Y.; Hung, F.; Lui, T.-S.; Chen, M.-Y.; Hsueh, H.-W. Effect of annealing on the microstructure and bonding interface properties of Ag-2Pd alloy wire. Microelectron. Reliab. 2015, 55, 1256-1261. [CrossRef]

9. Guo, R.; Hang, T.; Mao, D.; Li, M.; Qian, K.; Lv, Z.L.; Chiu, H. Behavior of intermetallics formation and evolution in Ag-8Au-3Pd alloy wire bonds. J. Alloys Compd. 2014, 588, 622-627. [CrossRef]

10. Feng, D.; Taskinen, P. Thermodynamic properties of silver-palladium alloys determined by a solid state electrochemical method. J. Mater. Sci. 2014, 49, 5790-5798. [CrossRef]

11. He, J.; Guo, Y.; Lin, Z. Effect of cleaver motion on interface deformation of thermo ultrasonic bonding. J. Shanghai Jiaotong Univ. $2008,42,716$.

12. Lu, L.; Han, L. Vibration characteristics of cleaver in ultrasonic bonding transducer system. Package Test Equip. 2008, 33, 1020.

13. Yao, L. The influence of cleaver on gold wire bonding. Hybrid Microelectron. 2003, 9, 31.

14. Goh, K.S.; Zhong, Z.W. Development of capillaries for wire bonding of low-kultra-fine-pitch devices. Microelectron. Eng. 2006, 83, 2009. [CrossRef]

15. Kim, I.J.; Kim, H.S.; Seo, M.Y. Advanced ceramics in wire bonding capillaries for semiconductor package technology. Mater. Sci. Eng. 2008, 498, 129. [CrossRef]

16. Cao, J.; Ding, Y.; Guo, T. Study on the influence of copper wire properties and bonding parameters on bonding quality. J. Mech. Eng. 2010, 46, 84-89. [CrossRef]

17. Qin, W.; Gao, J.; Yang, Z.; Wu, X.; Li, K. Finite Element Analysis of Lead Bonding Process Parameters. Mech. Des. Manuf. 2011, 17-19.

18. Xue, R. Effect of Ultrasonic Power and Bonding Pressure on the Bonding Quality of Gold Wire Thermal Ultrasonic Bonding; University of Electronic Science and Technology of China: Chengdu, China, 2016.

19. Tian, Y.H.; Wang, C.Q.; Lum, I.; Mayer, M.; Jung, J.P.; Zhou, Y. Investigation of ultrasonic copper wire second bonding on Au/Ni plated Cu substrates at ambient temperature. Mater. Process. Technol. 2008, 208, 179. [CrossRef]

20. Hou, T.; Su, C.H.; Chang, H.Z. Using neural networks and immune algorithms to find the optimal parameters for an $1 \mathrm{C}$ wire bonding process. Expert Syst. Appl. 2008, 34, 427.

21. Qiu, R. Study on the Influencing Factors of the First Bonded Point in Ultra-Fine Pitch Wire Bonding; Huazhong University of Science and Technology: Wuhan, China, 2004.

22. Pequegnat, A. Effect of gas type and flow rate on $\mathrm{Cu}$ free air ball formation in thermosonic wire bonding. Microelectron. Reliab. 2011, 51, 43-52. [CrossRef]

23. Yang, Z. Research on Image Recognition System of Intelligent IC Wire Bonder; Guangdong University of Technology: Guangzhou, China, 2005.

24. Dong, Y. Development and process research of thermoacoustic welding machine. Electron. Process. Technol. 2004, 25, 84-85.

25. Li, Y. Technical analysis of wire bonder. Spec. Equip. Electron. Ind. 2004, 33, 78-81.

26. Qiu, Y. Microjunctions in microwave multichip modules. Electron. Technol. 2005, 26, 319-322.

27. Huang, Y. Lead bonding technology in integrated circuit packaging. Electron. Packag. 2006, 6, 16-20.

28. Lu, K.; Wang, C.; Tian, Y. Study on the ultrasonic bonding FAB process and its influence of Cu lead. Electron. Technol. 2008, 29, 192-207.

29. Cao, J.; Ding, Y.; Cao, W. Research on wire breakage during the preparation of single crystal copper bonding wire. Acta Mech. Eng. 2010, 46, 84-89. [CrossRef]

30. Fan, H.; Ma, X.; Liu, X. Preparation of bonded silver wire. Gold 2017, 38, 6-9.

31. Cao, J.; Fan, J.; Gao, W. Effect of cold deformation and heat treatment on linear energy of Ag-4Pd bonded alloy. Acta Mech. Eng. 2016, 18, 92-97. [CrossRef]

32. Zhu, J. Research trends in alloying of bonded gold wires. Precious Met. 2002, 23, 57-61.

33. Guo, Y.; Yang, G.; Kong, J.; DAO, P.; Huan, W.; Guan, W. Development and application of gold bonding wires. Precious Met. 2009, $30,68-71$. 
34. Gong, Z.; Wang, X.; Wang, L. Progress in research and application of ceramic cleavers in microelectronics. Mater. Guide 2015, $29,90-91$.

35. Lando, D.J.; Mitchell, J.P.; Welsher, T.L. Conductive anodic filaments in reinforced Polymeric dielectrics: Formation and prevention. In Proceedings of the 17th Ebrahimi Annual, Reliability Physics Symposium, San Diego, CA, USA, 24-26 April 1979 ; pp. 39-43.

36. Lahti, J.N.; Delaney, R.H.; Hines, J.N. The characteristic wearout process in epoxy-glass printed circuits for high density electronic packaging. In Proceedings of the 17th Annual Reliability Physics Symposium, San Diego, CA, USA, 24-26 April 1979; pp. 39-43. 